\title{
NCI CTEP SDC Miscellaneous Neoplasm Category Terminology
}

National Cancer Institute

\section{Source}

National Cancer Institute. NCI CTEP SDC Miscellaneous Neoplasm Category

Terminology. NCl Thesaurus. Code C103024.

Miscellaneous Neoplasm is an NCl Cancer Therapeutic Evaluation Program (CTEP)

Simplified Disease Classification (SDC) category used to organize cancer-related disease

coding that harmonizes with and supports reporting based on the global standard

Medical Dictionary for Drug Regulatory Reporting (MedDRA) terminology. 